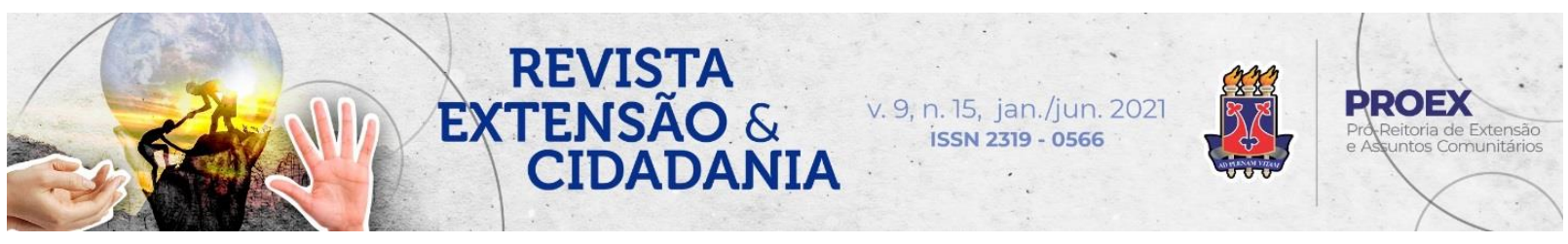

DOI: $10.22481 /$ recuesb.v9i15.8758

\title{
LUDICIDADE PARA ABORDAR CUIDADO COM OS ANIMAIS: AÇÕES EDUCATIVAS NAS ESCOLAS
}

\section{Ludicity to address care with animals: educational actions in schools}

Gabriele Marisco ${ }^{1}$

Yasmin Moreira Botelho²

\begin{abstract}
Resumo: O presente trabalho visa relatar a experiência de uma ação educativa do programa de extensão "Ações educativas sobre o cuidado com animais domésticos e de rua para promoção da saúde única/Ano II", em escolas de ensino fundamental de Vitória da Conquista, em 2019. As principais etapas da ação educativa consistiram em palestra dialogada, oficina de desenhos, customização de máscaras e jogo educativo. As escolas colaboraram com a realização das atividades, permitindo o envolvimento dos profissionais na organização das práticas propostas pelo projeto. Os resultados evidenciam que as atividades realizadas no projeto de extensão permitiram aos alunos a reflexão do tema, baseado na diversidade de atividades realizadas e nas discussões sobre a importância do cuidado com os animais. Conclui-se esse relato, convidando a sociedade, a universidade, os setores públicos, os representantes da sociedade (vereadores e prefeitos), secretarias de saúde e de educação municipal a fim de continuar essa discussão no município de Vitória da Conquista.
\end{abstract}

Palavras-chave: Empatia pelos animais. Saúde única. Ensino de respeito aos animais.

Abstract: The present work aims to report the experience of an educational action of the extension program "Educational actions on the care of domestic and street animals to promote unique health / Year II", in elementary schools in Vitória da Conquista, in 2019. The main stages of the educational action consisted of a dialogue, a drawing workshop, customization of masks and an educational game. Schools collaborated in carrying out the activities, allowing the involvement of professionals in the organization of the practices proposed by the project. The results show that the activities carried out in the extension project allowed students to reflect on the theme, based on the diversity of activities carried out and discussions about the importance of caring for animals. This report concludes by inviting society, the university, the public sectors, representatives of society (councilors and mayors), health and municipal

\footnotetext{
${ }^{1}$ Bióloga; Doutora em Biotecnologia. Professora da Universidade Estadual do Sudoeste da Bahia - UESB, Vitória da Conquista, Bahia, Brasil. Orcid: https://orcid.org/0000-0003-3072-8601 E-mail: gabrielemarisco@uesb.edu.br

2 Acadêmica do Curso de Psicologia, pela Universidade Estadual do Sudoeste da Bahia - UESB, Vitória da Conquista - Bahia, Brasil. Orcid: https://orcid.org/0000-0001-6114-9130 E-mail: yaasminmb@gmail.com
} 
education departments in order to continue this discussion in the municipality of Vitória da Conquista.

Keywords: Empathy for animals. Une health. Teaching respect for animals.

\section{Introdução}

Neste trabalho, são apresentados os resultados obtidos no Programa de Extensão “Ações educativas sobre o cuidado com animais domésticos e de rua para promoção da saúde única/Ano II”, realizado no ano de 2019. Os animais, assim como os humanos, precisam de cuidados e atenção. Antes de ter um animal, é essencial conhecer suas necessidades básicas, como alimentação, vacinação, higiene e moradia, além dos cuidados emocionais, como carinho e entretenimento, a fim de assegurar uma boa qualidade de vida para o animal.

No entanto, é notório que os maus-tratos e a falta de cuidados com os animais são constantes. Por isso, é de suma importância educar as crianças sobre essa temática o mais cedo possível, para aumentar a valorização da proteção animal e reduzir as atitudes de maus-tratos e abandono. Fazendo-se necessário conscientizar as crianças sobre os cuidados com os animais. Segundo Cordazzo e Vieira (2007, p. 92) "utilizar a brincadeira como um recurso escolar é aproveitar uma motivação própria das crianças para tornar a aprendizagem mais atraente".

Para Lira e Melo (2013, p. 1) “A inserção de projetos educacionais no interior das escolas públicas, dinamizam o ambiente de ensino-aprendizagem e torna possível uma maior interação do aprendiz com a realidade da educação básica”. As atividades educativas com crianças visam promover reflexão e mudança de comportamento com melhoras da saúde, podendo inferir que foi positivo e relevante essas ações.

O brincar é uma prática pedagógica que pode contribuir na abordagem do tema, nesse sentido, Ribeiro (2016, p. 46) afirma que "é brincando e jogando que a criança aprende de maneira mais natural, pois estas são atividades e vias de interesse da criança que despertam a curiosidade e o prazer em construir conhecimentos, interagindo com o meio físico e social”.

Ludicidade é um estado interno, que pode advir das mais simples às mais complexas atividades e experiências humanas. Não necessariamente a ludicidade provém do entretenimento ou das "brincadeiras". Pode advir de qualquer atividade que faça os nossos olhos brilharem. (LUCKESI, 2014, p. 18)

Revista Extensão \& Cidadania, v. 9, n. 15, p. 144-153, jan./jun. 2021.

ISSN 2319-0566 DOI: 10.22481/recuesb.v9i15.8758 
Dessa forma, percebe-se a necessidade e a importância de os profissionais da educação desenvolverem atividades lúdicas para tornar o aprendizado mais dinâmico e eficaz, saindo um pouco da rotina de aulas expositivas e trabalhando outras áreas de conhecimento com os alunos. Nessa perspectiva, o objetivo deste trabalho é apresentar uma ação extensionista do Programa de Extensão "Ações educativas sobre o cuidado com animais domésticos e de rua para promoção da saúde única/Ano II.

\section{Metodologia}

O trabalho foi realizado em três escolas municipais localizadas em bairros periféricos de Vitória da Conquista - BA, com alunos do $3^{\circ}$ e $4^{\circ}$ ano, de idades entre 6 a 10 anos. As instituições escolhidas foram: Escola Municipal Helena Cristalia Ferreira, Escola Municipal José Mozart Tanajura e Escola Municipal Batista Peniel.

As atividades aconteceram no ano de 2019, o projeto de extensão estabeleceu parceria com a Secretaria de Educação do município de Vitória da Conquista para realizar as atividades nas escolas municipais, e contou com disponibilização da lista de escolas e contato para agendamento das visitas. Nas escolas, foram desenvolvidas atividades e brincadeiras potencialmente lúdicas para melhor explicação e interação com o tema.

Inicialmente, houve uma palestra dialogada abordando os cuidados principais que se deve ter com os animais. Neste momento, as crianças participaram de forma ativa, citando exemplos de sua vivência. Em seguida, foi realizada uma oficina de desenho para que os alunos, de forma livre e através da arte, se expressassem acerca da sua relação com os animais. A terceira atividade foi a confecção de máscaras de "gatinho", disponibilizando lápis de cor e canetas, para um momento lúdico que despertasse a criatividade e a originalidade das crianças. Por fim, foi realizado um bingo, em forma de perguntas e respostas sobre o tema abordado durante a palestra, com o objetivo de averiguar o conhecimento adquirido pela turma (Figura 1).

Figura 1 - Etapas da ação educativa do programa de extensão. Vitória da Conquista, BA, 2019
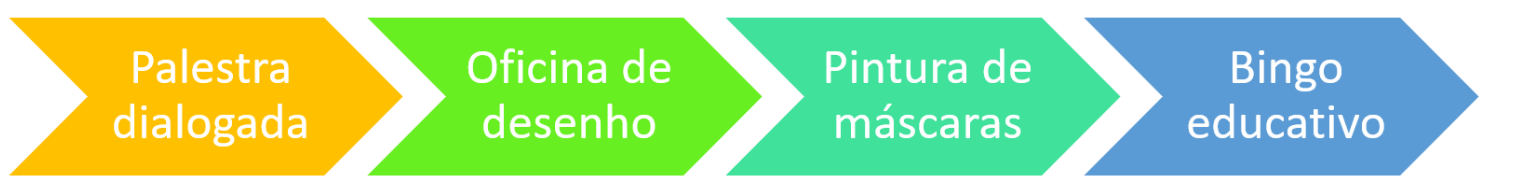

Fonte: Elaborada pelas autoras, 2021.

Revista Extensão \& Cidadania, v. 9, n. 15, p. 144-153, jan./jun. 2021.

ISSN 2319-0566 DOI: 10.22481/recuesb.v9i15.8758 
Salienta-se que esta atividade foi inspirada no projeto "Mundo Animal", da Espanha, que visa desenvolver o respeito pelos animais nos alunos das séries iniciais até aos alunos do secundário, desenvolvendo atividades sobre a empatia pelos animais, promovendo ao aluno a capacidade e gerar situações que ajudem os animais, fomentar a sensibilidade pelos animais para evitar maus-tratos e conscientizar sobre os cuidados e responsabilidade pelos animais.

\section{Resultados e discussão}

Aproximadamente 200 alunos do Ensino Fundamental das três escolas municipais de Educação Básica participaram dessa atividade. No primeiro momento, foi realizada uma palestra dialogada, em que foram explicados os cuidados que devemos ter com os animais, neste momento houve a participação intensa dos alunos, que davam exemplos e contavam casos familiares, sempre associados aos seus conhecimentos prévios e experiências (Figura 2).

Figura 2 - Coordenadora do projeto numa palestra dialogada. Vitória da Conquista, BA, 2019.

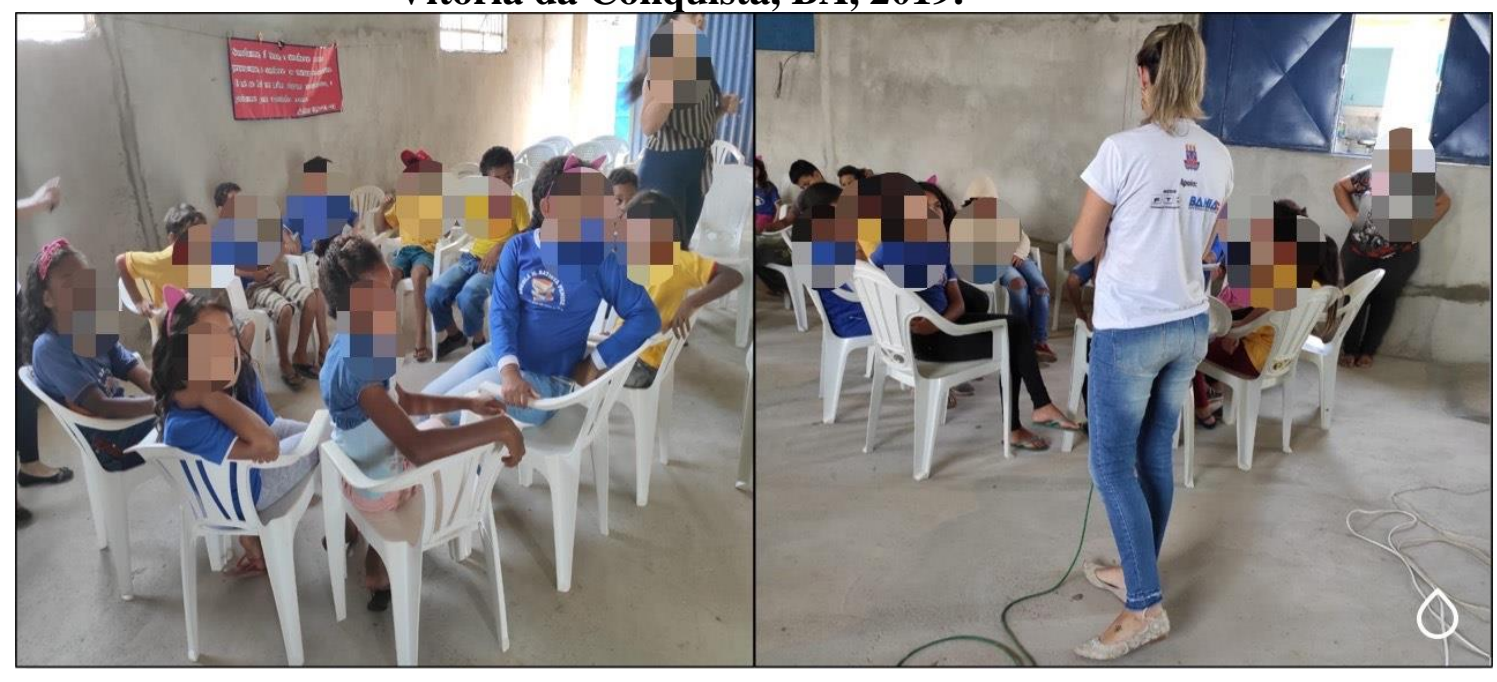

Fonte: Elaborada pelas autoras, 2019.

Foi observado que a maioria das crianças sabiam pouco a respeito dos cuidados com os animais. Tinham dificuldade em falar sobre as necessidades básicas de seus bichos, como qual alimento eles podiam comer, quantos banhos precisavam tomar no mês e as necessidades de vacinação e vermifugação.

Revista Extensão \& Cidadania, v. 9, n. 15, p. 144-153, jan./jun. 2021. 
As próximas etapas consistiram em produzir desenhos dos seus animais e customizar máscaras de gatinhos. Optou-se por essas atividades vinculadas à arte a fim de relacionar elementos com potencial lúdico (Figura 3).

Figura 3 - Desenhos dos alunos se referindo aos seus animais de estimação. Vitória da Conquista, BA, 2019.

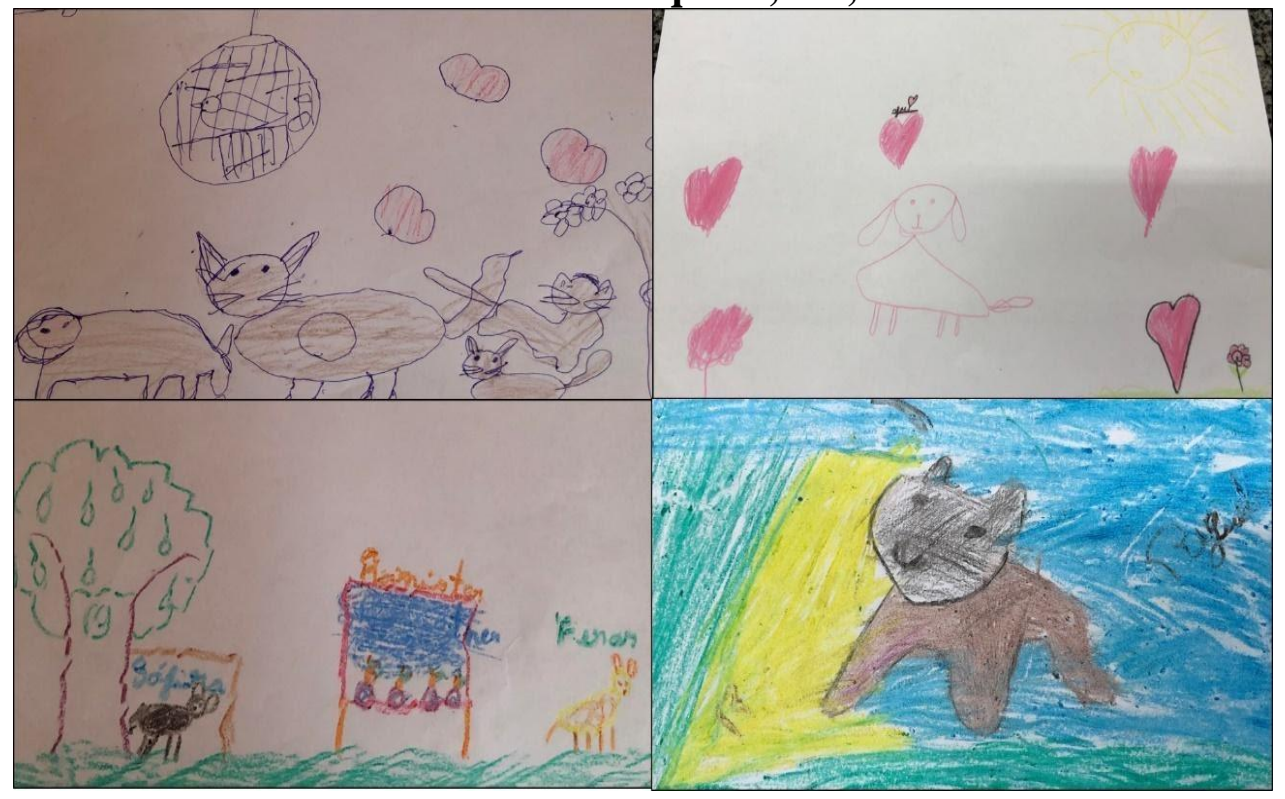

Fonte: Marisco et al., 2019.

Trabalho semelhante desenvolvido por Lisboa e Marisco (2021), foi possível identificar que a produção dos desenhos permitiu conhecer a percepção dos estudantes sobre a fauna urbana e sua relação com os animais, pois as ilustrações refletem suas perspectivas e sentimentos com os animais e seu bem-estar.

A atividade de personalização de máscaras de gatinho (Figura 4) foi um momento para os alunos usarem a criatividade e desenvolverem algo que poderiam usar no seu rosto e brincar. Esse momento apresentou-se de forma positiva e atendeu às expectativas das idealizadoras.

Revista Extensão \& Cidadania, v. 9, n. 15, p. 144-153, jan./jun. 2021. 
Figura 4 - A- Molde da máscara; B- Máscara entregue para os alunos; C- Alunos com máscaras de gatinhos. Vitória da Conquista, BA, 2019.

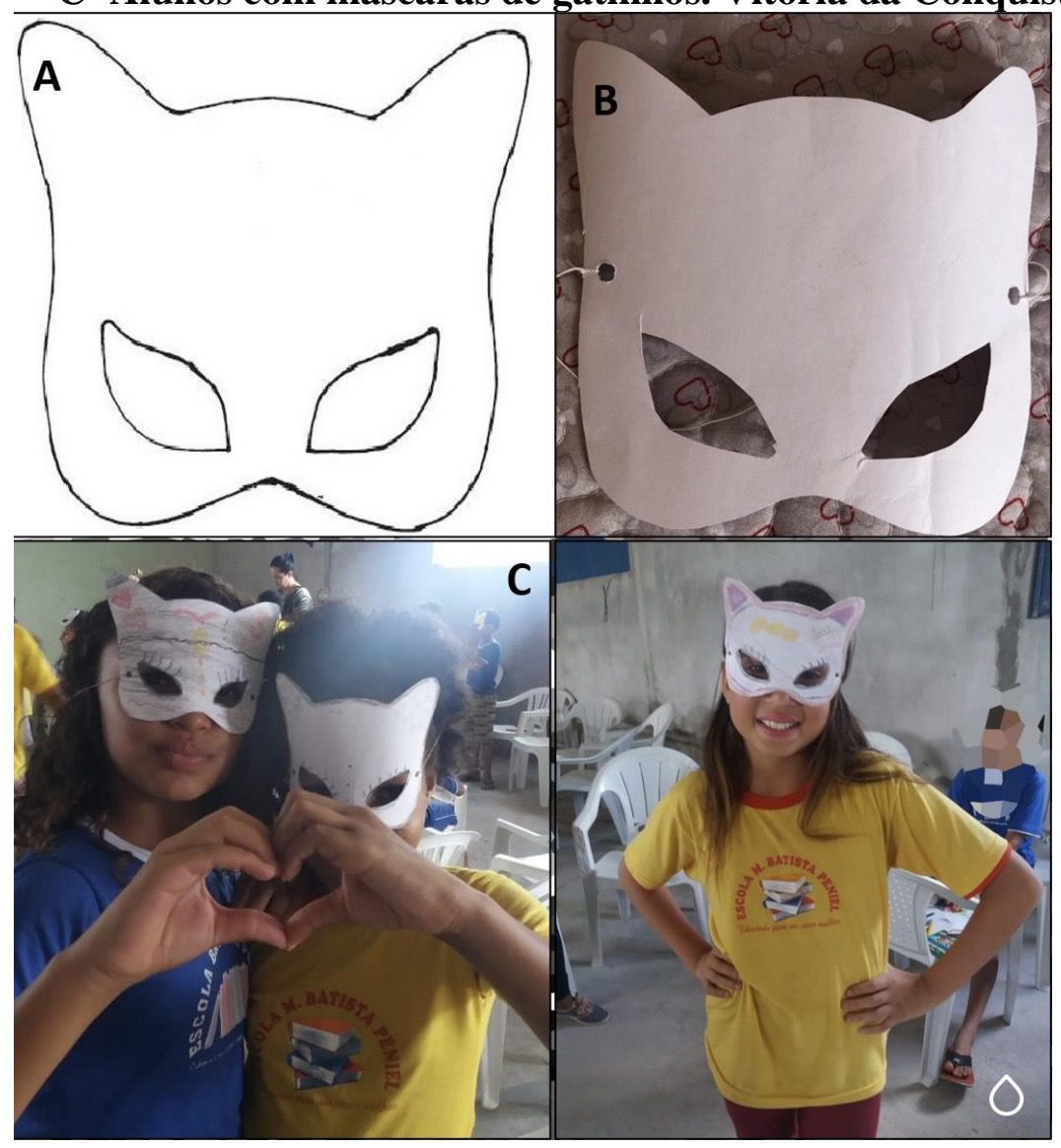

Fonte: Elaborado pelas autoras, 2019.

Para Vygotsky (1991, p. 67):

O brinquedo cria na criança uma nova forma de desejos. Ensina-a a desejar, relacionando seus desejos a um "eu" fictício, ao seu papel no jogo e suas regras. Dessa maneira, as maiores aquisições de uma criança são conseguidas no brinquedo, aquisições que no futuro tornar-se-ão seu nível básico de ação real e moralidade.

Pensar o lúdico como uma ferramenta de aprendizado e desenvolvimento na infância é de extrema importância, pois, através do brincar, a criança aprimora sua memória, linguagem, imaginação e outras funções psíquicas, sendo indispensável na prática educativa. $\mathrm{O}$ desenvolvimento da mediação didática lúdica, explorando a criatividade, a sensibilidade e o envolvimento da arte no ensino é estimulante, uma vez que as crianças se divertiram e

Revista Extensão \& Cidadania, v. 9, n. 15, p. 144-153, jan./jun. 2021.

ISSN 2319-0566 DOI: 10.22481/recuesb.v9i15.8758 
cultivaram suas habilidades, imaginações e percepções por meio das estratégias propostas (LISBOA; MARISCO, 2021).

Considerando o entusiasmo dos alunos, foi possível observar que a maioria dos alunos têm afetividade pelos animais, porém afirmam que os animais dos seus lares vivem soltos na rua, ou que ficam presos, acorrentados e em gaiolas, o que demostra a necessidade de mais atividades educativas nas escolas para colaborar com a consciência positiva sobre as relações com os animais.

Por fim, foi realizado um bingo com perguntas que foram trabalhadas durante a palestra, com o intuito de verificar o que foi aprendido. E para concluir a ação extensionista todos receberam um brinde simbólico produzido pela equipe do projeto, que era composto por um saquinho de pipoca, balas, pirulitos e um lápis decorado com um animal (Figura 5).

Figura 5 - Brindes confeccionados para presentear os alunos. Vitória da Conquista, BA, 2019.

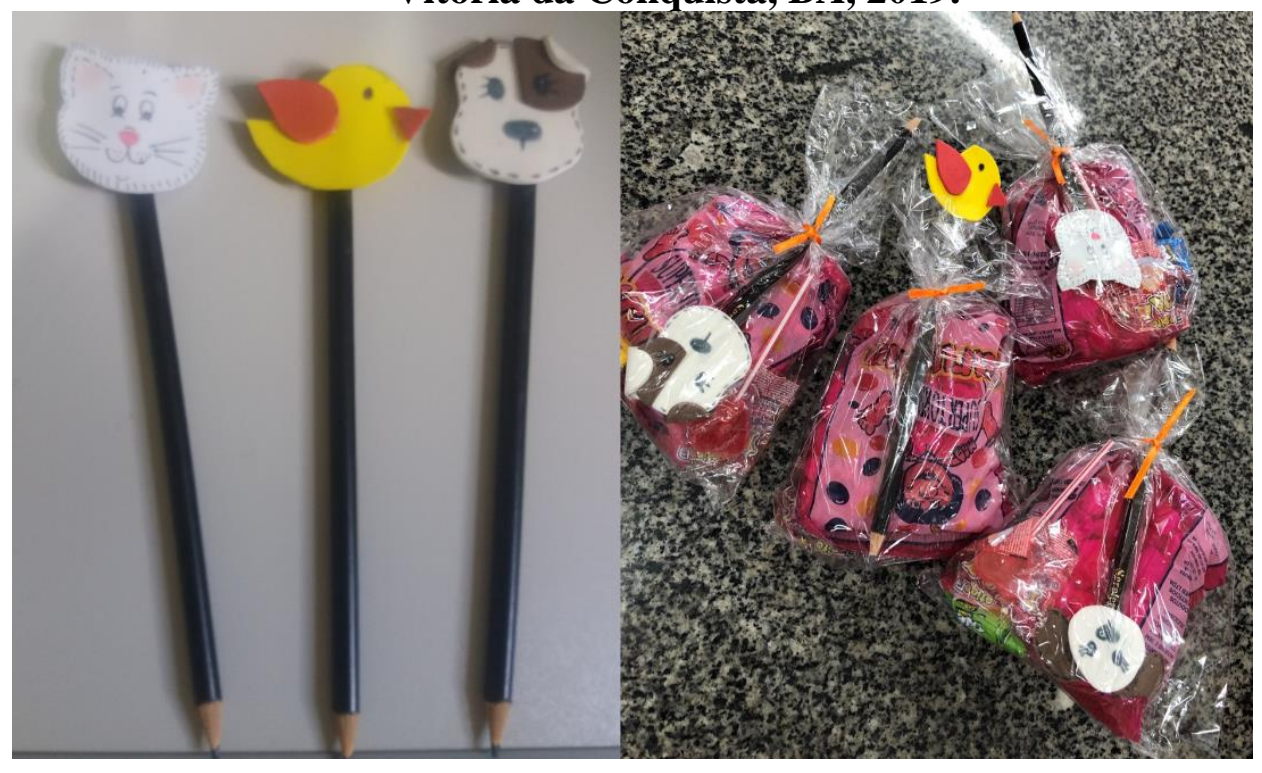

Fonte: Elaborado pelas autoras, 2019.

Salientamos a fundamentalidade da parceria dos professores das escolas envolvidas, que colaboraram com a realização das atividades, permitindo e contribuindo na organização das ações práticas propostas. Percebemos que, no decorrer das atividades extensionistas, os alunos experienciaram momentos de muitas informações, sendo possível iniciar a construção de

Revista Extensão \& Cidadania, v. 9, n. 15, p. 144-153, jan./jun. 2021.

ISSN 2319-0566 DOI: 10.22481/recuesb.v9i15.8758 
conhecimentos sobre respeito e cuidados com animais que, provavelmente, foram compartilhados com seus familiares e amigos.

Entretanto, salientamos aqui a importância da continuidade das ações educativas, visto que a comunidade precisa receber e participar de atividades sobre diferentes aspectos no âmbito de convivência com os animais domésticos. Visto que, a convivência com animais aumenta a transmissão de zoonoses e os tutores podem ter alergias ao pelo do animal. Além disso, a perda de um animal, seja por doença, desaparecimento ou roubo, pode acarretar muito sofrimento e angústia ao tutor, inclusive depressão (MIRANDA, 2011).

Outro aspecto que é relevante está relacionado com o número de pessoas que não se atentam aos cuidados com as fezes dos animais, esses resíduos podem em geral causar situações de risco para transmissão de doenças (SANCHEZ-ORTIZ; LEITE, 2010).

Nesse sentido, Lima (2010, p. 1459) adverte que:

O conhecimento sobre zoonoses nem sempre alcança a população exposta a riscos constantes. Assim, se faz necessário implementar ações de educação sanitária, as quais requerem a intervenção de autoridades relacionadas com a saúde e o saneamento ambiental, sendo extensivas à comunidade as informações precisas sobre riscos de contrair zoonoses e as formas de prevenilas.

\section{Considerações finais}

Considerando a experiência relatada, acreditamos que o objetivo da ação foi alcançado com sucesso, pois informações essenciais sobre o cuidado e respeito aos animais foram compartilhadas. Entretanto, considera-se indispensável a continuidade de ações nas escolas, com crianças a fim de abordar informações sobre cuidados e respeito com os animais, de modo a evitar os maus-tratos, abandonos e transmissão de zoonoses que é tão frequente na sociedade. Assim, concluímos esse relato, convidando a sociedade, a universidade, os setores públicos, os representantes da sociedade (vereadores e prefeitos), secretarias de saúde e de educação municipal a fim de continuar essa discussão no município de Vitória da Conquista.

Revista Extensão \& Cidadania, v. 9, n. 15, p. 144-153, jan./jun. 2021.

ISSN 2319-0566 DOI: 10.22481/recuesb.v9i15.8758 


\section{Agradecimentos}

Agradecemos aos coordenadores do projeto "Mundo Animal", da Espanha, que disponibilizaram material que norteou a elaboração das nossas atividades. $E$ agradecemos à PROEX/GEAC, da Universidade Estadual do Sudoeste da Bahia, pela concessão das bolsas e financiamento do projeto.

\section{Referências}

CORDAZZO, Scheila Tatiana Duarte; VIEIRA, Mauro Luís. A brincadeira e suas implicações nos processos de aprendizagem e de desenvolvimento. Estudos e Pesquisas em Psicologia, Rio de Janeiro, v. 7, n. 1, p. 92-104, abr. 2007.

LIMA, Ana Maria Alves; ALVES, Leucio Câmara; FAUSTINO, Maria Aparecida da Glória; LIRA, Nadja Maria Silva. Percepção sobre o conhecimento e profilaxia das zoonoses e posse responsável em pais de alunos do pré-escolar de escolas situadas na comunidade localizada no bairro de Dois Irmãos na cidade do Recife (PE). Ciências, Saúde Coletiva, Rio de Janeiro, v. 15, supl. 1, p. 1457-1464, jun. 2010.

LIRA, Cristiany Albuquerque; MELO, Risoleida Uchoa Pontes. Projeto PIBID: um relato de experiência na Escola Estadual de Ensino Fundamental e Médio Professor José Soares de Carvalho. III ENID / UEPB. Anais... Campina Grande: Realize, 2013. p. 1-7.

LUCKESI, Cipriano Carlos. Ludicidade e formação do educador. Revista Entreideias, Salvador, v. 3, p. 13-23, jul./dez. 2014.

MARISCO, Gabriele; CARDOSO, Marilete Calegari; ASSUNÇÃO, Renata Correia. Ateliê no ensino de ciências no ensino fundamental I: os sentidos de crianças sobre o respeito e cuidados pelos animais. ANPEd - Associação Nacional de Pós-Graduação e Pesquisa em Educação. Trabalho Completo - XXV EPEN - Reunião Científica Regional Nordeste da Associação Nacional de Pesquisa e Pós-Graduação em Educação. Anais... 2020.

MARISCO, Gabriele; LISBÔA, Daiana Kelly Moraes. Mediação didática lúdica: uma experiência com a produção de desenhos e reutilização de materiais reciclados. Revista Educação Pública, v. 21, n. 14, abr. 2021.

MIRANDA, Izabel Lobão. A importância do vínculo para os donos de cães e gatos nas famílias portuguesas. Dissertação (Mestrado Integrado em Medicina Veterinária) Universidade do Porto, Porto, p. 1-39, 2011.

RIBEIRO, Marcelo. Cultura lúdica digital: novas infâncias. Caderno de Filosofia e Psicologia da Educação, v. 9, n. 1, p. 41-57, 2016.

Revista Extensão \& Cidadania, v. 9, n. 15, p. 144-153, jan./jun. 2021.

ISSN 2319-0566 DOI: 10.22481/recuesb.v9i15.8758 
SANCHEZ-ORTIZ, Iván A; LEITE, Maurício A. Fatores de risco da transmissão de zoonoses por costumes da população de Ilha Solteira, Brasil. Revista Salud Pública, v.13, n. 3, p. 504$513,2011$.

VYGOTSKY, Lev. S. A formação social da mente. 4. ed. São Paulo: Martins Fontes, 1991.

Recebido: 03.05.2021

Aceito: 21.06.2021

Revista Extensão \& Cidadania, v. 9, n. 15, p. 144-153, jan./jun. 2021.

ISSN 2319-0566 DOI: 10.22481/recuesb.v9i15.8758 